\title{
Prevalence of Methicillin Resistant Staphylococcus aureus and Antibiotic Susceptibility Pattern in a Tertiary Hospital in Nepal
}

\author{
Laxmi Kant Khanal, ${ }^{1}$ Ram Prasad Adhikari, ${ }^{1}$ Ankita Guragain ${ }^{1}$ \\ 'Department of Microbiology, Nepal Medical College Teaching Hospital, Jorpati, Kathmandu, Nepal.
}

\begin{abstract}
Background: Methicillin resistant Staphylococcus aureus is a global health challenge nowadays creating problem in
antibiotic therapy. This study was aimed to generate resistance pattern of Methicillin resistant Staphylococcus aureus to
various antibiotics in order to formulate antibiotic policy for control of Methicillin resistant Staphylococcus aureus in
Nepal.
Methods: This was a cross-sectional study conducted at the department of Clinical Microbiology, Nepal Medical
College Teaching Hospital, from April 2015 to March 2016. A total of 142 S. aureus isolated from various clinical
specimens. were screened for Methicillin resistant Staphylococcus aureus by cefoxitin disc method according to Clinical
and Laboratory Standards Institute guidelines.
Results: Out of 142 S. aureus isolates, 30 (21.1\%) were detected as Methicillin resistant Staphylococcus aureus by
cefoxitin disc method. Most of the Methicillin resistant Staphylococcus aureus (25/30) were isolated from pus which
were collected from OPD patients. Antibiotic sensitivity pattern showed all Methicillin resistant Staphylococcus aureus
isolates were sensitive to vancomycin.
Conclusions: Prevalence of Methicillin resistant Staphylococcus aureus was found to be $21.1 \%$, and all Methicillin
resistant Staphylococcus aureus appear $100 \%$ sensitive to vancomycin.
Keywords: Antibiotic Susceptibility Test, MRSA, Nepal, Prevalence.
\end{abstract}

\section{INTRODUCTION}

Antibiotic resistance is a global health challenge nowadays. Methicillin resistant Staphylococcus aureus (MRSA), mediated by mecA gene, is one of the biggest problem throughout the world including Nepal. ${ }^{1-4}$ Infections caused by MRSA are mainly nosocomial and are increasingly reported from many countries worldwide. ${ }^{3-9}$ The prevalence of MRSA varies in different parts of the globe ranging from $1-30 \%$ in Europe, $5-40 \%$ in Asian countries, $10-50 \%$ in USA and UK. The prevalence rate of MRSA in Nepal is reported to be $15-69 \%$ from different areas in the country. ${ }^{6-9}$

The emergence of antibiotic resistant bacteria creates great problem in antibiotic therapy. So, this study was designed to find the antibiotic sensitivity pattern of MRSA in order to formulate antibiotic policy for control of MRSA in Nepal.

\section{METHODS}

A prospective cross-sectional study was conducted at Clinical Microbiology Laboratory of Nepal Medical College Teaching Hospital during April 2015-March 2016 after obtaining ethical approval from Nepal Medical College-Research and Ethical Sub-committee. A total of 142 S.aureus isolated from various clinical specimens were included in the study.

MRSA were detected by cefoxitin disc method. For this, lawn culture was performed on Mueller Hinton agar plate using the broth culture of S.aureus with turbidity adjusted to $0.5 \mathrm{McF}$ arland standard. Then, a cefoxitin disc (30 mcg) was kept on the lawn culture after it had been left dry for about 5 min. Finally, the agar plate was incubated aerobically at $37^{\circ} \mathrm{C}$ for $18 \mathrm{hr}$. The strains showing diameter of zone of inhibition of equal or less than $21 \mathrm{~mm}$ were considered as MRSA.

For antibiotic susceptibility test, standard microbiological technique was followed. ${ }^{10}$ The antibiotic discs used were ampicillin, ciprofloxacin, co-trimoxazole, cephalexin, cefoxitin, erythromycin, clindamycin, cloxacillin, gentamycin, and vancomycin. Data were analysed using SPSS-version 16.
DOI: $\underline{\text { http://dx.doi.org/10.3126/ }}$

jnhrc.v16i2.20305
Correspondence: Mr Laxmi Kant Khanal, Department of Microbiology, Nepal Medical College, Jorpati, Kathmandu, Nepal. Email: khanallk@yahoo.com, Phone: +9779810814101. 
Prevalence of Methicillin Resistant Staphylococcus aureus and Antibiotic Susceptibility Pattern

RESULTS

Out of 142 S. aureus isolated from various clinical specimens, total $30(21.1 \%)$ were found to be MRSA (Figure 1).

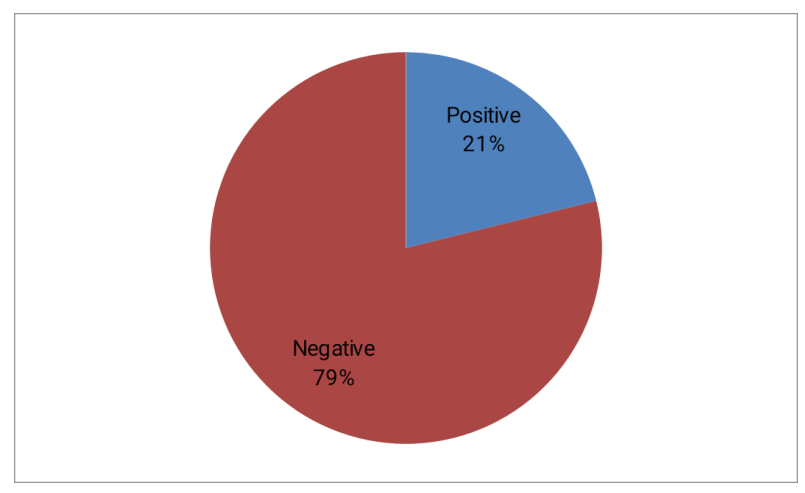

\section{Figure 1. Prevalence of MRSA.}

Among various clinical specimens, MRSA were mostly isolated from pus $(25 / 30)$ and MRSA isolates were mostly seen among OPD patients (Table 1 ).

\begin{tabular}{|c|c|c|c|c|}
\hline \multirow{2}{*}{ S.N. } & \multirow{2}{*}{ Clinical sample } & \multicolumn{2}{|c|}{ Number of MRSA } & \multirow[t]{2}{*}{ Total } \\
\hline & & In patient & Out patient & \\
\hline 1 & Urine & 1 & 0 & 1 \\
\hline 2 & Blood & 0 & 0 & 0 \\
\hline 3 & Pus & 8 & 17 & 25 \\
\hline 4 & Sputum & 1 & 0 & 1 \\
\hline 5 & Wound Swab & 2 & 0 & 2 \\
\hline \multirow[t]{2}{*}{6} & Tissue culture & 1 & 0 & 1 \\
\hline & Total & & & 30 \\
\hline
\end{tabular}

Antibiotic sensitivity pattern showed that, all MRSA isolates were sensitive only to vancomycin and resistant to cephalexin (90\%), erythromycin $(63.3 \%)$, ciprofloxacin (33.3\%), and co-trimoxazole (30\%) (Table 2 ).

\begin{tabular}{|c|c|c|}
\hline Antibiotics used & MRSA $(n=30)$ & MSSA $(n=112)$ \\
\hline Ampicillin & 100 & 58.90 \\
\hline Ciprofloxacin & 33.33 & 11.60 \\
\hline Cotrimoxazole & 30.0 & 25.89 \\
\hline Cephalexin & 90.0 & 4.46 \\
\hline Cefoxitin & 100 & 0.0 \\
\hline Erythromycin & 63.33 & 31.25 \\
\hline Clindamycin & 56.66 & 24.10 \\
\hline Cloxacillin & 93.33 & 0.0 \\
\hline
\end{tabular}

\begin{tabular}{lll} 
Gentamicin & 26.66 & 9.82 \\
vancomycin & 0.0 & 0.0 \\
\hline
\end{tabular}

\section{DISCUSSION}

Our study findings showed that, the prevalence of MRSA is $21.1 \%$ which is similar to findings of other various studies in different parts of the world. ${ }^{7,9-13}$ however, our reports did not match with the finding of previous researchers. ${ }^{1,14}$ which might be due to differences in inclusion criteria of the samples in our study. The high prevalence of MRSA in this study might be due to hospital based specimens.

MRSA were mostly isolated from pus specimen in our study which might be due to isolation of more $S$. aureus from pus compared to other clinical specimens which is similar to findings of other various studies too. ${ }^{16-19}$ This might be due to high prevalence of MRSA in deep seated lesions compared to superficial infections. ${ }^{1}$ Our report indicates high prevalence of MRSA among OPD patients compared to in-patients which contrasts with findings of other previous research findings conducted elsewhere in the world. ${ }^{15-24}$ This discrepancy in our study may be due to the frequent use of the antibiotic by the people without the clinician prescription and also may be due to the improper use of antibiotics by the individuals which is not so common in other part of the world. This might have led to development of drug resistance by bacteria to various commonly used antibiotics, specially indicating community acquired MRSA. This finding makes scientific community alert for conducting community based research study also on MRSA and other various drug resistant bacteria. Further, our finding is also in consistent with the findings of other studies in Nepal where community acquired MRSA infection is high. ${ }^{11}$ However, due to unequal number of samples taken to compare, we can't say MRSA isolation rate is high among OPD patients compared to inpatients and this becomes limitation of our study.

Our study showed that all MRSA isolates were sensitive to vancomycin and resistant to cephalexin, erythromycin, and ciprofloxacin which is similar to the findings of various research reports. ${ }^{20-24}$ This indicates vancomycin remains as first choice against MRSA infections with $100 \%$ treatment efficacy till date.

\section{CONCLUSIONS}

Our study showed that there is high prevalence of MRSA among clinical specimens, especially pus, and MRSA are $100 \%$ sensitive to vancomycin till date. These findings 
recommend using proper antibiotics to reduce MRSA infections in Nepal which includes; discussion with physicians and the public about the impact of MRSA, surveillance and detection of MRSA, strict enforcement of infection control strategies in hospitals, and prudent use of vancomycin for treatment of MRSA related infections.

\section{REFERENCES}

1. Khanal LK, Jha BK. Prevalence of methicillin resistant Staphylococcus aureus (MRSA) among skin infection cases at a hospital in Chitwan, Nepal. Nepal Med Coll J. 2010; 12(4): 224-8. [PMID]

2. Joshi S, Ray P, Manchanda V. Methicillin resistant Staphylococcus aureus (MRSA) in India: Prevalence and susceptibility pattern. Indian J Med Res. 2013; 137(2): 363-9. [PMID][PMCID]

3. Lynne D, Geoffrey W, Coomb S. Methicillin resistant S. aureus in Western Australia. J Emerging Infect Dis. 2015; 11(10): 1584-90.[DOI]

4. Shima MA, Adebayoo S, Mark PN, Mamadoukaba M. Molecular epidemiology of MRSA in USA: a systemic review. J Front Microbiol. 2015; 6: 348.[PMCID]

5. Bhatt CP, Karki BMS, Baral B, Gautam S, Shah A, Chaudhary A. Antibiotic susceptibility pattern of S. aureus and methicillin resistant $S$. aureus in a tertiary care hospital. J Pathol Nepal. 2014; 4: 548-51.[DOI]

6. Tiwari HK, Sapkota D, Das AK, Sen MR. Assessment of different tests to detect methicillin resistant S. aureus. Southeast Asian J Trop Med Public Health. 2009; 40:8016. [PMID]

7. 7. Kumari N, Mahopatra TM, Singh YI. Prevalence of MRSA in a tertiary care hospital in Eastern Nepal. J Nepal Med Assoc. 2008; 47:53-6.[PMID]

8. Subedi S. Antimicrobial susceptibility patterns of clinical isolates of S. aureus in Nepal. J Clin Microbiol Infect Dis. 2005; 11: 235-7.[DOI]

9. Kshetry AO, Pant ND, Bhandari R et al. Minimum inhibitory concentration of vancomycin to MRSA isolated from different clinical samples at a tertiary care hospital in Nepal. Antimicrob Resist Infect Control. 2016; 5: 27. [DOI]

10. Miles RS, Amyes SGB. Mackie and McCartney Practical Medical Microbiology. London: Churchill Livingstone; 1996: 151-60.

11. Rijal KR, Pahari N, Shrestha B. Prevalence of MRSA in school children in Pokhara. Nepal Med Coll J. 2008; 10: 192-5. [PMID]
12. Ansari S, Nepal HP, Gautam R et al. Threat of drug resistant S. aureus to health in Nepal. BMC Infect Dis. 2014; 14: 157.[DOI]

13. Khanal R, Sah P, Lamichhane P, Lamsal A, Upadhaya S, Pahwa VK. Nasal carriage of MRSA among health care workers at a tertiary care hospital in Western Nepal. Antimicrob Resist Infect Control. 2015; 4: 39.[PMCID] [DOI]

14. Mukhiya RK, Shrestha A, Rai SK. Prevalence of MRSA in hospitals of Kathmandu Valley. Nepal Journal of Science and Technology. 2012; 13(2): 185-90. [DOI]

15. Shrestha B, Pokhrel Bm, Mahopatra TM. Study of nosocomial isolates of $S$. aureus with special reference to MRSA in a tertiary care hospital in Nepal. Nepal Med Coll J. 2009; 11: 123-6. [PMID]

16. Sanjana RK, Singh R, Chaudhary N. Prevalence and antimicrobial susceptibility pattern of MRSA in CMS Teaching Hospital. Journal of College of Medical SciencesNepal. 2010; 6: 1-6. [DOI]

17. Shakya B, Shrestha S, MitraT. Nasal carriage rate of MRSA at NMC - Birgunj, Nepal. Nepal Med Coll J. 2010; 12: 26-9. [PMID]

18. Huang H, Flynn NM, King H, Monchad D, Morita M, Cohen SH. Comparision of community associated MRSA and hospital associated MRSA infections. J Clin Microbiol. 2006; 44: 2423-7. [PMID][PMCID] [DOI]

19. Rai SK, Tuladhar NR, Shrestha HG. Methicillin resistant S. aureus in a tertiary medical care centre, Nepal. Indian J Med Microbiol. 1990; 8: 108-9.

20. Rajbhandari R, Manandhar SP, Shrestha J. Comparative study of MRSA and its antibiotic susceptibility pattern in indoor and outdoor patients in Bir Hospital, Nepal. Nepalese J Microbiol. 2003; 1: 62-5.

21. Shrestha B, Pokhrel BM, Mahopatra TM. Phenotypic characterization of nosocomial S. aureus isolates in special reference to MRSA. J Infect Dev Ctries. 2009; 3: 554-60. [PMID]

22. Niami TS, LeDell KH, Como SK et al. Comparision of community and health care associated MRSA infection. J Amer Med Assoc. 2003; 290: 2976-84.[PMID][DOI]

23. Uday SC, Harish BN, Umesh KP et al. Prevalence of MRSA in JIPMER hospital. Indian J Med Microbiol. 1997; 15: 137-8.

24. Rajduraipandi K, Mani KR, Paneerselvem K, Mani M, Vaskar M, Manikandan P. Prevalence and Antibiotic Susceptibility pattern of MRSA: A multicentre study. Indian J Med Microbiol. 2006; 24: 34-8.[PMID] 